\title{
Factors Affecting Information System Satisfaction from a Two-Dimensional Perspective
}

\author{
Kuang-Ting Cheng \\ Department of Information Management, National United University, Taiwan \\ Email: KTCheng@nuu.edu.tw
}

How to cite this paper: Cheng, K.-T. (2019) Factors Affecting Information System Satisfaction from a Two-Dimensional Perspective. Open Journal of Business and Management, 7, 568-596. https://doi.org/10.4236/ojbm.2019.72040

Received: February 23, 2019

Accepted: March 26, 2019

Published: March 29, 2019

Copyright (อ 2019 by author(s) and Scientific Research Publishing Inc. This work is licensed under the Creative Commons Attribution International License (CC BY 4.0).

http://creativecommons.org/licenses/by/4.0/

\section{(c) (i) Open Access}

\begin{abstract}
Studies evaluating information management personnel's satisfaction with IT systems tend to employ one-dimensional linear thinking before identifying the associated affecting factors. However, this method cannot clearly define the true cognition of users or confirm how the factors affect satisfaction. The present study combined Herzberg's two-factor theory and the Kano model with expectation disconfirmation theory to form a two-phase study. First, a thorough literature review and modified Delphi method were conducted to consolidate the dimensions of user satisfaction and associated variables, which found that "confirmation" in the expectation disconfirmation theory is closely related to satisfaction. Subsequently, a questionnaire was designed using the determined variables and based on expectation disconfirmation theory. The questionnaire was distributed using convenience sampling to employees at companies in Taiwan, with 369 valid responses returned. Using this innovative method, this study successfully divided the variables that affect the satisfaction of information systems into four types: motivators and hygiene, performance, and useless factors.
\end{abstract}

\section{Keywords}

Research Method, Information System Satisfaction, Two-Factor Theory, Kano Model, Expectation Disconfirmation Theory

\section{Introduction}

Numerous empirical studies have suggested that information managers are responsible for user satisfaction with information systems [1]. Researchers have often assumed satisfaction to be a straight line with satisfaction and dissatisfaction at opposite ends, believing that users' cognition accompanied by identified 
factor affecting satisfaction fall at some point along the line. In other words, studies have considered low satisfaction to be representative of dissatisfaction; such thinking originates from the statistical process linear regression, which is used to verify the results. This research method can only identify the factors that affect satisfaction with an information system, but it cannot distinguish at what stage the factors affect satisfaction. Furthermore, linear methods may diminish the power of the factors affecting satisfaction when the effect is above or below a certain threshold.

Unlike the emerging field of information management, the concept of satisfaction has a long history in other fields, especially business management. Among relevant theories, Herzberg's two-factor model is one of the most widely recognized tools in studies related to satisfaction, and it is mainly used to explore the factors associated with satisfaction and dissatisfaction expressed by employees toward their organization. The central idea is that satisfaction is not a one-dimensional concept, but comprises two separate concepts of satisfaction and dissatisfaction. Factors that lead to employee satisfaction are called "motivators"; organizations do not necessarily require these factors, but employee satisfaction increases rapidly if these factors are present. Factors that lead to dissatisfaction are called "hygiene factors"; these factors must exist in an organization because without them employees quickly become dissatisfied [2].

Furthermore, in the field of marketing, the Kano model is often used to explore customer satisfaction. This model suggests that each of the various attributes of products provided to customers individually affect customer satisfaction. The impact of some attributes is linear; thus, customer satisfaction increases correspondingly when these attributes improve. However, the impact of other attributes is nonlinear, which indicates that their performance can lead to an increase or sharp decline in customer satisfaction in a curve [3]. In these well-known theories and models developed for studying satisfaction, personal cognition cannot be expressed using a linear distribution wherein the two ends represent two extremes; instead, layers of cognition exist between these extremes. When multiple layers exist in an individual's cognition of satisfaction, linear thinking no longer suffices, because such simplification is unable to grasp an individual's inner state. This indicates that recommendations for practice made based on linear systems are imprecise.

We believe that user satisfaction with information systems is similar to employee job satisfaction and customer satisfaction. Users have multiple layers of cognition in terms of satisfaction with information systems.

By examining the field of information management, we found that the most commonly used theory for exploring satisfaction was the expectation disconfirmation theory. Oliver believed that people's sense of satisfaction with certain things originates from confirmation after comparing expectations with perceived performance before and after coming into contact with the actual event or product [4] [5] Oliver proposed that a comparison between expectations and 
perceived performance can derive three results. The first result, "confirmation," is achieved when the perceived performance matches the expectation. The second result, "positive disconfirmation," is achieved when the perceived performance is superior to the expectation. The third result, "negative disconfirmation," is achieved when the perceived performance is inferior to the expectation. We conducted the present study under the assumption that if the results of positive and negative confirmation underwent appropriate statistical analysis, we would be able to validate and determine a group of factors that affect the level of satisfaction as well as identify the multiple layers of satisfaction associated with information systems.

This study was thus designed on the foundation of Herzberg's two-factor theory and the Kano model, which were combined with the expectation disconfirmation theory to form a two-phase study. An empirical study with a large sample was implemented to explore the relationship between the disconfirmation status and satisfaction of each individual predisposing variable, thereby attempting to sort the factors that affect the level of satisfaction with information systems into multiple layers, namely motivators, hygiene factors, performance factors, and useless factors.

\section{Literature Review}

\subsection{Information System Satisfaction}

Studies examining problems related to information system satisfaction have found factors affecting satisfaction in several dimensions, including the system, interpersonal relationship, organizational management, and project development. The system dimension mainly explores user satisfaction with the attributes of an information system; for example, the quality and functions of the system and the quality of the information presented. Many researchers have found that the quality of systems and information are significant factors that affect user satisfaction with information systems [6] [7]. The most notable study on the dimensions of a system was conducted by DeLone and McLean [8], who pioneered the IS success model. They proposed that users generate personal cognition of their satisfaction with the information and system quality provided by an information system, and this perceived satisfaction indirectly affects the whole organization. Another study indicated that high information and system quality is necessary for a successful information system [8]. A decade after their 1992 study, DeLone and McLean reinterpreted the IS success model. They argued that information and system quality are insufficient for a system to achieve success; service quality is also required, and they therefore added service quality as a necessary criterion [9].

In terms of the organizational management dimension, user satisfaction is affected by whether management provides sufficient resources. When users use the information system in an organization, they may occasionally require workrelated resources and support, and they may feel dissatisfied with the informa- 
tion system if sufficient support or backup from management is unavailable. Furthermore, whether an organization provides education and training on the operation of its information system affects user satisfaction [10] [11] [12].

Last, for the project development dimension, researchers have found that whether users participate in the process of system development affects their overall satisfaction with the information system [13] [14] [15]. When users participate in the process of software development, they are provided with sufficient opportunities to communicate with system development personnel regarding the functions and interfaces required during system analysis, and thus the completed information system fits the users' requirements. This prevents development personnel from developing an information system that is disliked by the end users. Overall, user participation can be deemed to play an important role in the development process. In summary, system satisfaction is often discussed in the areas of organizational management, project management and information management.

\subsection{Two-Factor Model}

As previously mentioned, the concept of satisfaction has long been developed in fields outside information management. Among the relevant theories, Herzberg's two-factor model is one of the most widely recognized models for studies related to satisfaction. Herzberg believed that employees' satisfaction with their jobs is hierarchical, such as in Maslow's hierarchy of needs. Some factors are related to physical and security needs, which are necessary because without them, employee satisfaction would not increase. These factors are called the hygiene factors. Other factors are related to social needs and the need for respect, which increase employees' job satisfaction. These factors are called motivators [2].

Herzberg's two-factor model has been widely used in other academic areas, such as customer service, product marketing, and product design. Juran [16] used the two-factor model to study airlines' customer service, determining that the comfort of the cabin and lavatories and punctuality of flights are hygiene factors, whereas customized services such as helping passengers transfer and check in are motivators. Furthermore, the two-factor theory has been employed in studies on information management; for example, Zhang and von Dran [17] used the two-factor model to explore web design, finding that the reputation of a website, its privacy, and its entertainment factors are motivators, and its basic functions and navigation protection are hygiene factors. In addition, S. Lee, Shin, and Lee [18] proposed that system quality is a hygiene factor because low system quality prompts customers to cut down on their use of mobile data services. By contrast, information quality is a motivator because when it is higher, customers tend to increase their use of mobile data services. In terms of collation, although the two-factor theory is often applied in many fields, there is no good measurement method to make the theory more scalable.

\subsection{Kano Model}

The Kano model was developed to explore customer satisfaction in the field of 
marketing, and it is another crucial theoretical framework for discussing satisfaction. This model proposes that the quality of any product can be divided into three qualities-must-be, attractive, and one-dimensional-and customers are more satisfied if such qualities exist [3]. Researchers in the fields of marketing and consumer psychology have used this model to identify the key attributes recognized by consumers in order to facilitate quality improvement and enhancement. This has led to a significant breakthrough in quality management [19]. In addition, such thinking has been applied to research on information management. User satisfaction in the various dimensions of each attribute of a website's design can be derived using the Kano model. Research has shown that website navigation and whether the information provided is biased are the "must-be" qualities of web design. In addition, whether the users enjoy the website (enjoyment) or acquire knowledge and skills from it are the "attractive" qualities; and the "privacy," "technical support," and "credibility" of a website are the "one-dimensional" qualities [20]. Moreover, some researchers have combined the Kano model with service quality to develop a series of service-related attributes [21]. This literature review reveals that the Kano model presents factors affecting satisfaction in a multilayered manner, and despite also containing the concept of linear thinking, it is completed by the addition of two extra dimensions.

\subsection{Expectation Disconfirmation Theory}

Oliver [4] [22] proposed the expectation disconfirmation theory, the main concept of which is that consumers determine how satisfied they are with a product or service by comparing their expectation before purchase with its actual performance. Notable characteristics of this process are the dimensions of "confirmation" or "disconfirmation." Most related studies have assumed that all factors triggering satisfaction-related cognition have direct effects on consumer satisfaction. However, Oliver argued that disconfirmation was the main predisposing factor for satisfaction as well as a significant mediator between triggering factors and consumer satisfaction. Consumers have initial expectations of a product that are based on experience, word-of-mouth from friends and family, and information, as well as promises provided by marketers and competitors. They are initiated from predictions of what the products or services have to offer. Oliver asserted that expectation is formed by two key elements: the probability of occurrence and evaluation of the content of the occurrence. When consumers come into contact with a product, the perceived performance is formed, which is emotional cognition generated from actual experience. Later, consumer satisfaction is formed after the consumers cross-reference the perceived performance with their prepurchase expectation.

Viewing information system satisfaction within an organization from the perspective of the expectation disconfirmation theory is similar to the aforementioned consumer expectations. Users form certain expectations before they use 
the information system, particularly concerning the quality of the information system and the changes (e.g., the greater convenience that the system may bring to their work). After users experience the system first hand, they form an emotional perception. This perception may correspond to or differ from their expectations, and the result of this confirmation or disconfirmation affects users' satisfaction with the information system. Studies have confirmed that the expectation disconfirmation theory has a certain amount of interpretative power for the satisfaction dimension. Although many studies have explored information system satisfaction from this perspective, most have viewed it using one-dimensional linear thinking. Examining Herzberg's two-factor theory reveals that the multidimensional concept of satisfaction should exist in personal cognition. Therefore, this study integrated Herzberg's two-factor theory, the Kano model, and the expectation disconfirmation theory under the belief that the factors must be processed through customer disconfirmation before they can fully interpret satisfaction. Furthermore, the factors affecting information system satisfaction and user disconfirmation can be divided into the following four quadrants: Herzberg's motivators, Herzberg's hygiene factors, performance factors that are linearly correlated with satisfaction, and useless factors that have no impact on satisfaction. This four-quadrant concept is illustrated in Figure 1.

1) Motivators: When a significant correlation is found between positive disconfirmation and satisfaction, but the correlation between negative disconfirmation and satisfaction appears to be nonsignificant, the factor is a motivator. Herzberg's operational definition for a motivator is that high performance of

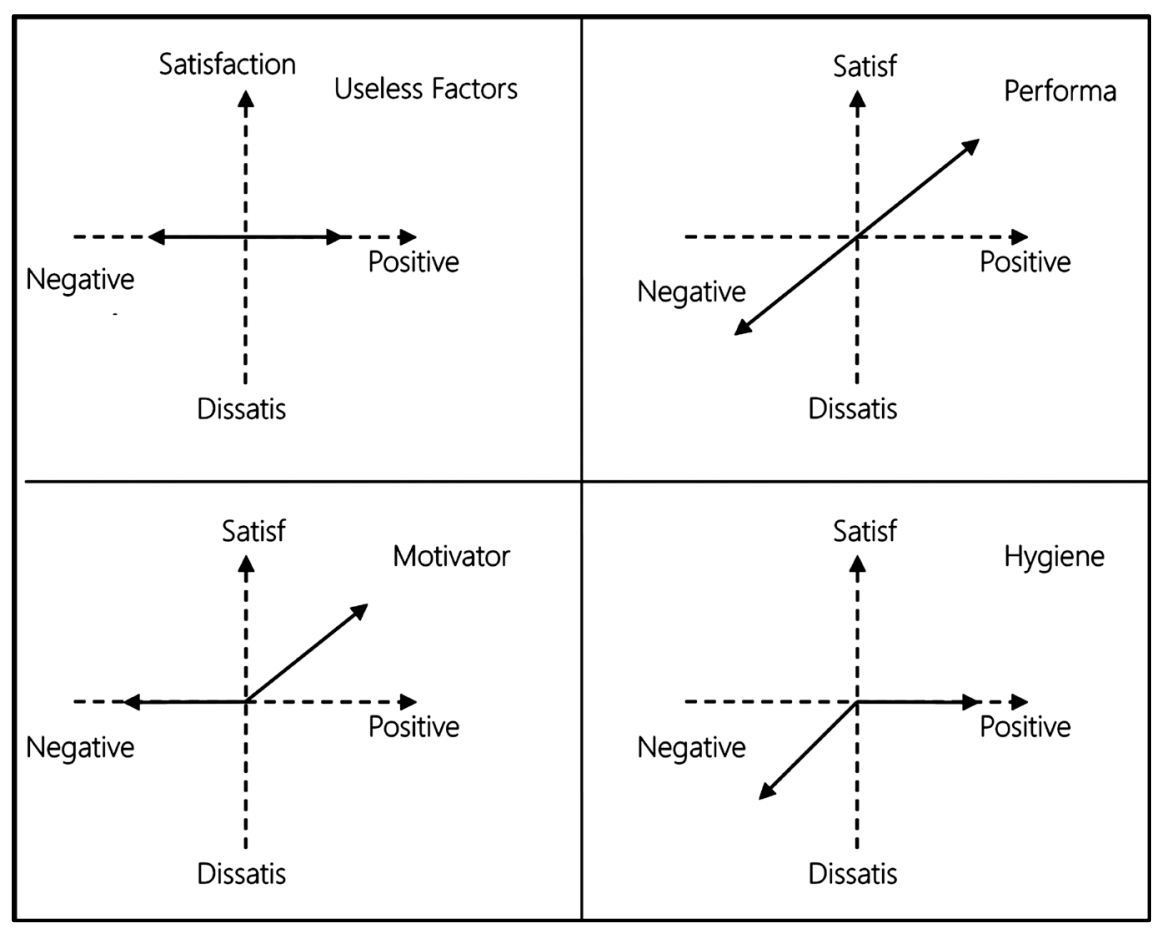

Figure 1. Multidimensional satisfaction analysis factor concept model (developed by this study). 
attributes in this category delights users.

2) Hygiene factors: When the correlation between positive disconfirmation and satisfaction is nonsignificant, but the correlation between negative disconfirmation and satisfaction is significant, the factor is a hygiene factor. Herzberg's operational definition for a hygiene factor is that the performance of attributes in this category provides users with a sense of dissatisfaction.

3) Performance factors: When the correlation between positive disconfirmation and satisfaction as well as the correlation between negative disconfirmation and satisfaction is significant, the factor is a performance factor. This result has the same definition as information system satisfaction measured by the linear model; the attributes in this category are positively correlated with user satisfaction.

4) Useless factors: When no significant correlation exists between positive disconfirmation and satisfaction or the correlation between negative disconfirmation and satisfaction, the factor is a useless factor. This means that the performance of attributes in this category is not related to user satisfaction or dissatisfaction.

\section{Methodology}

This study adopted a series of stringent research methodologies to identify the factors affecting information system satisfaction. The study was conducted in two stages. The first stage focused on verifying the variables that affect users' satisfaction with information systems. We performed a literature review based on Herzberg's two-factor theory to categorize the dimensions. The second stage was an empirical analysis using the information satisfaction impact variables verified in the first stage to design a questionnaire based on the expectation disconfirmation theory. To establish a correct sample framework, we adopted an appropriate distribution method to obtain empirical data. Through a two-step statistical analysis, we sorted the factors affecting information system satisfaction into motivators, hygiene factors, performance factors, and useless factors.

\subsection{Stage 1: Verifying Variables That Affect Information System Satisfaction}

We consolidated the variables that were relevant to information system satisfaction from the literature. Because numerous studies exist on information system satisfaction, and the data are scattered across various journals, we limited our search to seven major journals. First, we collected data from the following six journals recommended by the Association for Information Systems: Management Information Systems Quarterly, Journal of Management Information Systems, Information Systems Research, Journal of the Association for Information Systems, Information Systems Journal, and European Journal of Information Systems. To prevent the omission of variables significant to information system satisfaction, we added Information \& Management to the list of references for 
data collection. The reason for adding Information \& Management was twofold: Information \& Management is a major academic journal in the field of information management, and its publications have an extensive collection of relevant articles.

After the main references were selected, we launched a keyword search in the seven international journals from the first issue until 2017 to find all articles relevant to information system satisfaction. Subsequently, we extracted all the variables identified in the essays, regardless of whether they showed significance. To target the variables for information system satisfaction, we used the modified Dephi method to ask the scholars and experts in the field of information [23]. There are 9 scholars and 20 industry experts involved in this process. After three rounds of Dephi method, they combined the variables that had similar operational definitions and categorized them into various dimensions. Finally, 28 variables were identified that affected information system satisfaction, and they were assigned to six dimensions (Appendix A1).

\subsection{Stage 2: Collection and Analysis of Empirical Data}

\subsubsection{Questionnaire Development}

In the second stage of the study, we developed a questionnaire based on the information system satisfaction variables derived from the literature. Spreng [24] consolidated all questionnaires based on the theory into five major categories, which can be summarized into direct measurements of "expectation" and "perceived performance," the score of "disconfirmation" derived from subtraction, and direct measurement of the differences between the scores of the respondents. Among them, the calculation of the additive difference model (ADM) is considered the most precise [24]. The ADM suggests that researchers first measure respondents' inclination toward disconfirmation; specifically, they should determine whether a respondent's inclination is toward positive or negative disconfirmation before asking their degree of disconfirmation. This mode of questioning reduces the bias from subtracting the scores attributed to expectations and perceived performance separately; thus, more information regarding the level of disconfirmation can be derived with higher precision.

In this study, we developed 41 factors affecting information system satisfaction from the 28 variables derived in the first stage, and we designed a questionnaire along the axle of the ADM based on Herzberg's two-factor theory and the Kano model complemented by the expectation disconfirmation theory to measure the multidimensional factors affecting information system satisfaction (see Appendix A2 for the detailed questionnaire).

\subsubsection{Sampling and Testing}

This study aimed to determine the factors affecting information system satisfaction in organizations. Therefore, the target subjects were users of information systems. Because the sample population was large, more stringent sampling methods such as stratified sampling or cluster sampling were unsuitable for this 
study. Thus, the research adopted convenience sampling to select the test subjects. Before the official questionnaires were sent out, we conducted a pretest at eight companies in Hsinchu, Taiwan, aiming to detect problems in the questionnaire and those that were likely to occur during the survey. In this stage, 18 questionnaires were returned. The 18 test subjects were interviewed to ensure that they understood the test questions clearly and to inquire about any problems during survey distribution; for example, whether company information security systems restrict transmissions of electronic file formats. After considering the pretest results, the final questionnaire survey was implemented through both online and paper-based formats. We found the paper-based format necessary because the test subjects were users of information systems in organizations, some of which have strict controls over access to external links. Furthermore, we implemented two formats to ensure the success of data collection and prevent interference caused by restrictions from a single data collection mode.

This study was implemented over 1 month. We established an online survey platform on Google and sent the questionnaire link to people we knew in various companies. They then shared the link with other employees. When someone responded that their internal information security system disallowed links to external sites or the electronic file format we used, we printed hard copies of the questionnaire and asked our contacts to distribute them. To maximize the return rate, we offered 100 convenience store gift vouchers, each worth NT\$100 for a lottery draw, to those who were willing to leave their email addresses. A total of 369 questionnaires were returned, and after eliminating the incomplete or nonconforming samples, 369 were verified as valid responses. See Table 1 for details.

\subsubsection{Statistical Analysis}

Statistical analysis was conducted using a two-step process. The first step was a sectioned correlation analysis to compute the result's groupings of the factors affecting information system satisfaction. Linear regression was employed for the statistical analysis, and the test participants were divided into two groups for each factor by whether they identified the attribute as positive or negative disconfirmation. Each factor was then subjected to linear regression analysis. If significant correlation was found between positive disconfirmation and satisfaction, but the correlation between negative disconfirmation and satisfaction did not reach a level of significance, the factor was identified as a "motivator." If the correlation between positive disconfirmation and satisfaction did not reach a level of significance, but significant correlation was found between negative disconfirmation and satisfaction, the factor was identified as a "hygiene factor." If the correlation between positive disconfirmation and satisfaction and between negative disconfirmation and satisfaction was positive, the factor was identified as a "performance factor." If no significant correlation was found between positive disconfirmation and satisfaction or between negative disconfirmation and satisfaction, the factor was identified as a "useless factor." The grouping in step 1 is presented in Table 2. 
Table 1. Demographic variables.

\begin{tabular}{|c|c|c|c|c|c|c|c|}
\hline & & Freq. & Pct. & & & Freq. & Pct. \\
\hline \multirow[t]{3}{*}{ Sex } & Male & 210 & $56.91 \%$ & Age & 20 to 30 & 28 & $7.59 \%$ \\
\hline & Female & 155 & $42.01 \%$ & & 26 to 30 & 128 & $34.69 \%$ \\
\hline & Not answered & 4 & $1.08 \%$ & & 31 to 35 & 98 & $26.56 \%$ \\
\hline \multirow{7}{*}{$\begin{array}{l}\text { Years of work } \\
\text { (years) }\end{array}$} & Less than 1 & 81 & $21.95 \%$ & & 36 to 40 & 58 & $15.72 \%$ \\
\hline & 1 to 5 & 151 & $40.92 \%$ & & 41 to 45 & 20 & $5.42 \%$ \\
\hline & 6 to 10 & 81 & $21.95 \%$ & & 46 to 50 & 16 & $4.34 \%$ \\
\hline & 11 to 15 & 29 & $7.86 \%$ & & 51 to 56 & 7 & $1.90 \%$ \\
\hline & 16 to 20 & 15 & $4.07 \%$ & & Not answered & 14 & $3.79 \%$ \\
\hline & 21 to 30 & 11 & $2.98 \%$ & Education & $\begin{array}{l}\text { High school/occupational } \\
\text { high school and lower }\end{array}$ & 9 & $2.44 \%$ \\
\hline & Not answered & 1 & $0.27 \%$ & & Associate degree & 19 & $5.15 \%$ \\
\hline \multirow[t]{9}{*}{ Industry } & Information Technology & 157 & $42.55 \%$ & & Bachelor's degree & 141 & $38.21 \%$ \\
\hline & Manufacturing & 90 & $24.39 \%$ & & Master's degree and higher & 195 & $52.85 \%$ \\
\hline & Medical & 47 & $12.74 \%$ & & Not answered & 5 & $1.36 \%$ \\
\hline & Services & 36 & $9.76 \%$ & Professional & Information technology & 144 & $39.02 \%$ \\
\hline & Education & 12 & $3.25 \%$ & background & Engineering & 83 & $22.49 \%$ \\
\hline & Finance \& Banking & 11 & $2.98 \%$ & & Business administration & 80 & $21.68 \%$ \\
\hline & Public services & 3 & $0.81 \%$ & & Medical professional & 26 & $7.05 \%$ \\
\hline & Aviation & 1 & $0.27 \%$ & & Design & 8 & $2.17 \%$ \\
\hline & Others & 12 & $3.25 \%$ & & Education & 6 & $1.63 \%$ \\
\hline \multirow{10}{*}{$\begin{array}{c}\text { No. of } \\
\text { employees }\end{array}$} & Less than 100 & 58 & $15.72 \%$ & & Liberal arts & 4 & $1.08 \%$ \\
\hline & 100 to 500 & 66 & $17.89 \%$ & & Others & 5 & $1.36 \%$ \\
\hline & 500 to 1000 & 57 & $15.45 \%$ & & Not answered & 13 & $3.52 \%$ \\
\hline & 1000 to 5000 & 68 & $18.43 \%$ & Computer & 5 and less & 5 & $1.36 \%$ \\
\hline & 5000 to 10000 & 26 & $7.05 \%$ & $\begin{array}{l}\text { experience } \\
\text { (years) }\end{array}$ & 6 to 10 & 86 & $23.31 \%$ \\
\hline & 10000 to 30000 & 20 & $5.42 \%$ & & 11 to 15 & 147 & $39.84 \%$ \\
\hline & 30000 and more & 9 & $2.44 \%$ & & 16 to 20 & 88 & $23.85 \%$ \\
\hline & Not answered & 65 & $17.62 \%$ & & 21 to 25 & 20 & $5.42 \%$ \\
\hline & & & & & 26 to 30 & 7 & $1.90 \%$ \\
\hline & & & & & Not answered & 16 & $4.34 \%$ \\
\hline
\end{tabular}

Table 2. Multidimensional factor distribution.

\begin{tabular}{cccc}
\hline & & Correlation between negative disconfirmation and satisfaction \\
\cline { 3 - 4 } & & Significant & Nonsignificant \\
\hline $\begin{array}{c}\text { Correlation between positive disconfirmation } \\
\text { and satisfaction }\end{array}$ & Significant & Performance factor & Motivator \\
& Nonsignificant & Hygiene factor & Useless factor \\
\hline
\end{tabular}


Subsequently, the factors affecting information system satisfaction were grouped into four types. However, the grouping in step 1 only analyzed the data based on the significance or insignificance of the correlation without comparing the correlation between the two groups of positive disconfirmation and negative disconfirmation. Therefore, we decided that a second step was required for comparison between the groups to achieve precise grouping of the four types of factors.

Step 2 focused on the performance factors identified in step 1, which were tested using the population regression function (function 1) proposed by [25] [26]. When a performance factor was identified in step 1 but tested with significance in the population regression test in step 2, as well as when the slope of positive disconfirmation was greater than that of negative disconfirmation, we grouped the factor as a motivator. By contrast, if the slope of positive disconfirmation was smaller than that of negative disconfirmation, we grouped the factor as a hygiene factor.

$$
\mathrm{t}=\frac{\operatorname{Path}_{\text {sample_1 }}-\operatorname{Path}_{\text {sample_2 }}}{\left[\sqrt{\frac{(m-1)^{2}}{(m+n-2)} * S \cdot E_{\text {sample1 }}^{2}+\frac{(n-1)^{2}}{(m+n-2)} * S \cdot E_{\text {sample } 2}^{2}}\right] *\left[\sqrt{\frac{1}{m}+\frac{1}{n}}\right]}
$$

Path $_{\text {sample_1 }}$ : path coefficient of positive disconfirmation on satisfaction

Path $_{\text {sample_ }}$ : path coefficient of negative disconfirmation on satisfaction

$S . E_{\text {sample } 1}$ : standard error of path coefficient of positive disconfirmation on satisfaction

$S . E_{\text {sample2 }}$ standard error of path coefficient of negative disconfirmation on satisfaction

$m$ : positive disconfirmation population sample size

$n$ : negative disconfirmation population sample size

Through the aforementioned statistical analysis, we discovered that if we used the linear model, all 41 factors affecting satisfaction were significantly correlated with information system satisfaction. By contrast, the sectioned analysis elucidated the effect of each factor affecting information system satisfaction at various stages, and it also revealed more information for in-depth exploration (see Appendix A3 for details on the statistics of each factor). After consolidating the 41 factors and the total scores of system quality, service quality, and information quality, we identified 25 motivators, 7 hygiene factors, 9 performance factors, and 3 useless factors. See Table 3 for details.

\section{Conclusions and Limitations}

\subsection{Conclusions}

This research integrated Herzberg's two-factor theory and the Kano model. Using a questionnaire survey based on the expectation disconfirmation theory and two-step statistical analysis, we successfully grouped the factors affecting information system satisfaction identified in past studies into four types: motivators, hygiene factors, performance factors, and useless factors. Regarding system quality, 
Table 3. Master list of factors affecting satisfaction and their types.

\begin{tabular}{|c|c|c|c|}
\hline Variable & Type of factor & Variable & Type of factor \\
\hline System quality & Hygiene factor & Personal recognition & Motivator \\
\hline System quality—accessibility & Hygiene factor & Information quality & Performance factor \\
\hline System quality—reliability & Performance factor & Information quality—accuracy & Motivator \\
\hline System quality_response time & Hygiene factor & Information quality_completeness & Motivator \\
\hline System quality_flexibility & Hygiene factor & Information quality_currency & Motivator \\
\hline System quality_integration & Hygiene factor & Information quality_format & Motivator \\
\hline System quality (total score) & Hygiene factor & Information quality (total score) & Motivator \\
\hline System ease of use & Hygiene factor & Perceived usefulness & Motivator \\
\hline Compatibility with the experience of system use & Performance factor & Confirmation of expectation & Motivator \\
\hline IT department service quality & Performance factor & Uncertainty & Motivator \\
\hline Service quality—reliability & Performance factor & Complexity & Performance factor \\
\hline Service quality_responsiveness & Motivator & Autonomy & Motivator \\
\hline Service quality_assurance & Motivator & Feedback & Motivator \\
\hline Service quality_empathy & Performance factor & Power & Useless factor \\
\hline Service quality (total score) & Motivator & Role conflict & Motivator \\
\hline Computer policy & Useless factor & Effectiveness & Motivator \\
\hline Security policy & Motivator & Efficiency & Motivator \\
\hline Training & Performance factor & Work security & Motivator \\
\hline Management support & Performance factor & Work replacement & Useless factor \\
\hline Customer relation & Motivator & Computer skill growth & Motivator \\
\hline Supervisor relation & Motivator & Work skill growth & Motivator \\
\hline Supervisor recognition & Motivator & Self-efficacy & Motivator \\
\hline
\end{tabular}

overall system quality and detailed attributes such as accessibility, response time flexibility, and integration were all identified as hygiene factors, except for "reliability," which was identified as a performance factor. Therefore, users believe that an organization's information system should have high quality, which includes easy accessibility, fast system responses, flexibility to meet users' needs, and the ability to integrate data from other areas. However, the reliability of an information system can affect users' satisfaction depending on the system's stability.

In addition to the identified attributes of system quality, the well-known technology acceptance model developed for the information management field proposes the ease-of-use attribute, which was identified by this study as a hygiene factor. Users believe that if they must use an organization's information system to work, it must be easy to use. If not, users feel dissatisfied. However, this attribute has now been well developed and users no longer feel satisfied by its presence. Furthermore, we identified the factor of experience compatibility 
proposed by the diffusion of innovations theory as a performance factor, which means that when users use the information system in their organization, the more the operation interface or methods are compatible with their experience from operating other systems, the more satisfied they feel. By contrast, if they feel that they must learn an interface again, they feel dissatisfied.

In terms of an IT department's service quality, overall service quality was identified as a performance factor. The rate of user satisfaction with the information system operates on the perception of overall service. We examined the four attributes of service quality and found that reliability and empathy were performance factors. This indicated that user satisfaction is affected by IT personnel. Users are satisfied when IT personnel fulfill their promises to users and when users feel that IT personnel are willing to understand the difficulties they have using a system. By contrast, users feel dissatisfied if they perceive that IT personnel do not stick to their promises and fail to recognize their experiences. The two attributes of responsiveness and assurance of service quality were identified as motivators in this study, which showed that users feel satisfied if IT departments can provide immediate solutions. However, if IT departments are unable to complete relevant tasks, this does not make users feel dissatisfied.

In addition to the factors relating to IT departments and information systems, studies have determined several factors regarding organizational management. In our study, we determined computer policy to be a useless factor. User satisfaction is not affected by whether a company has a reward or punishment system for making effective use of an information system. By contrast, for information security, users feel highly satisfied if a company has a strong information security policy, but if a company does not have one, they do not feel dissatisfied. In computer training policy and management support, users are more satisfied with an information system if a company provides comprehensive computer training and if management provides sufficient resources. However, they feel dissatisfied with an information system if the training is insufficient or management does not provide support.

Furthermore, this study found users' interpersonal relationships after using an information system to be a motivator. Users feel highly satisfied with an information system if they can form strong relationships with their customers and supervisors after they start using the system. In addition, if they receive more recognition from their supervisors and feel pleased with their performance using the system, they feel highly satisfied with it. However, if none of these conditions are met, users feel dissatisfied with the information system.

Overall information quality was identified as a performance factor, which means that the quality of information provided by a system directly affects users' satisfaction. Except for complexity and power relating to working with a system, the other factors affecting satisfaction were all identified as motivators. Regarding the complexity of using a system, users were satisfied if a system makes their work easier; however, if a system does not do so, they are not dissatisfied. Therefore, this factor was identified as a performance factor. In terms of person- 
al power, some researchers have argued that information systems change the power and status of employees and affect their satisfaction. However, we identified personal power as a useless factor, because it does not affect users' satisfaction or dissatisfaction with an information system. Factors relating to working with the system, such as perceived usefulness, confirmation of expectation, autonomy, feedback, role conflict, effectiveness, and efficiency were identified as motivators. We found that positive disconfirmation of these factors affecting user satisfaction but negative disconfirmation does not. Regarding perceived usefulness, users are more satisfied if they feel that an information system is useful and helpful. Moreover, users' satisfaction increases if an information system makes the content of their work clearer. For autonomy, users feel more satisfied if they are able to arrange their own work more freely after using a system. Regarding feedback, users are more satisfied if they can ascertain the effectiveness of their work through feedback from a system. Furthermore, regarding role conflict, users are more satisfied with an information system if their roles and duties are defined more clearly. User satisfaction also increases if a system improves the quality and speed of work.

In the advancement and growth category, except for work replacement, which was identified as a useless factor, all other factors were identified as motivators. Regarding work replacement, users' perception of whether they would be replaced by an information system is relevant to their level of satisfaction with the system. Consequently, regarding job security, users feel more satisfied if their jobs are more secure after using a system. As for skill growth, users feel satisfied if they can acquire knowledge and skills related to using computers and their work. Simultaneously, they feel more satisfied with an information system if it increases their confidence to complete their work independently. However, none of the aforementioned factors affect users' information system satisfaction if they are not achieved.

\subsection{Contribution to Practice}

In this study, we analyzed and identified the following six major impact dimensions relating to information system satisfaction: Management Information Systems (MIS) department and information systems, company computer policy and administration, interpersonal relationships and recognition, work, performance, and advancement and growth. This analysis provides managers with clarity on the factors affecting information system satisfaction and can serve as a reference for management decisions.

For the MIS department dimension, managers of organizations should attempt to make company information departments more service oriented. IT personnel are company employees, equal to other employees in an organization; however, because modern IT has become a significant asset for organizations, IT personnel should play a more active role in helping users utilize information systems. Furthermore, managers should reinforce the concept of service science 
in their IT employees to promote higher information system satisfaction [27].

Users care for the stability of an information system and whether it is easy to use. Managers must ensure the stability and speed of system response at all times; specifically, they must focus on IT infrastructure, for example by establishing a database, maintaining networking facilities, ensuring an uninterrupted power supply, upgrading computer functions, and backing up data. Although these technologies are now highly mature, managers must pay extra attention to problems in these areas. Users do not allow for even temporary system breakdowns because when the system is interrupted, users' work is affected. This study found that such a situation increases user dissatisfaction [28].

Regarding companies computer policies, this study found that computer-related training courses are the basics of management policy. Several multinational technology companies in Taiwan, such as MediaTek, UMC, and Winbond, have been implementing training courses for years, and they have dedicated whole departments to managing relevant practices. However, in other industries (e.g., medical care), employees' computer skills training is insufficient, which indirectly affects employees' information system satisfaction. This is an area that managers must reinforce [29]. Furthermore, this study found that users feel more satisfied if a company provides a comprehensive information security policy. This means that information security may not be a necessary condition, but nonetheless users feel more secure if the information system is protected from attacks; this sense of security increases their satisfaction with the information system [30].

In addition, we found that users feel more satisfied if an information system benefits their work. Therefore, managers must conduct a detailed analysis on work requirements when introducing any information system to an organization. Only information systems that help users complete their work will create satisfied users. Furthermore, if an organization intends to develop their own system, managers must ensure that the system analysts collaborate with users throughout the development because only then will it be a useful system that can satisfy users and truly help them complete their work [31].

\subsection{Contributions to Academic Development and Future Studies}

The most critical contribution of this study is the successful integration of Herzberg's two-factor theory and the Kano model. This study used the expectation disconfirmation theory to design a questionnaire and performed statistical analysis using a logical two-step method, which rectified the defects of previous methods based on Herzberg's two-factor theory. Through this multidimensional grouping of factors affecting satisfaction in the present study, researchers can locate more information and understand how users are affected by each factor across the various cognitive layers. These groupings provide a system for verifying the factors proposed previously and facilitate understanding of which layers play more significant roles. Through future in-depth research, we will explore 
the relationships among users' cognition, emotions, and behaviors, as well as the roles of the various factors in users' behaviors.

Furthermore, we believe that various factors affecting satisfaction can be derived from information systems with different orientations. Because members of an organization must use the information systems inside the organization, such systems differ in terms of design and users from the website systems of e-commerce businesses, where users are voluntary. Therefore, the motivators, hygiene factors, and performance factors derived from these two systems are distinct. Moreover, paid and free websites hosting e-commerce activities differ substantially in terms of the mentioned scenarios, and therefore, the factors affecting satisfaction derived from the systems also differ greatly. These represent viable directions for future research.

\subsection{Research Limitations}

Although this study used stringent research methodologies, it has some limitations that should be considered when interpreting the results. First, although we conducted a thorough search on the impact variables identified in seven international information management journals, further undisclosed variables still exist; however, because of their nonsignificant results they were omitted. Moreover, the research participants were organizational users. Because this is a large population, we were unable to use more stringent stratified or cluster sampling methods, and therefore there may have been errors when estimating the population.

In designing the questionnaire design, this study adopted the expectation disconfirmation theory, focusing on the measurement standards of positive disconfirmation and negative disconfirmation. However, we overlooked the fact that options for answers in this layer are mostly derived from discoveries from relevant studies. If the questionnaire design includes confirmation of the options at this layer, most answers will fall into this layer, and a two-step analysis can be used to apply Herzberg's two-factor theory and the Kano model to determine information system satisfaction. Furthermore, we explored 41 factors affecting satisfaction, and thus we were unable to measure each factor with three or four questions. Instead, we had to use one question for each factor, which is another limitation of this study.

Finally, the biggest limitation of this research is that we could not use the same statistical method to develop a theoretical model. This is because the positive and negative disconfirmations of the questions were inconsistent, and therefore could not be calculated simultaneously. We were only able to identify the factors that belonged to the four types and then explore the theoretical model in terms of the various factors and follow-up behaviors.

\section{Conflicts of Interest}

The author declares no conflicts of interest regarding the publication of this paper. 


\section{References}

[1] Peppard, J., Edwards, C. and Lambert, R. (2011) Clarifying the Ambiguous Role of the CIO. MIS Quarterly Executive, 10, 31-44.

[2] Herzberg, F. (1959) The Motivation to Work. John Wiley \& Sons, New York.

[3] Kano, N., Seraku, N., Takahashi, F. and Tsuji, S. (1984) Attractive Quality and Must-Be Quality. Journal of the Japanese Society for Quality Control, 14, 39-48.

[4] Oliver, R.L. (1980) A Cognitive Model of the Antecedents and Consequences of Satisfaction Decisions. Journal of Marketing Research, 17, 460-469. https://doi.org/10.1177/002224378001700405

[5] Oliver, R.L. and Rust, R.T. (1997) Customer Delight: Foundations, Dindings, and Managerial Insight. Journal of Retailing, 73, 311-336. https://doi.org/10.1016/S0022-4359(97)90021-X

[6] Nelson, R.R., Todd, P.A. and Wixom, B.H. (2005) Antecedents of Information and System Quality: An Empirical Examination within the Context of Data Warehousing. Journal of Management Information Systems, 21, 199-235. https://doi.org/10.1080/07421222.2005.11045823

[7] Teo, T.S.H., Srivastava, S.C. and Jiang, L.I. (2008) Trust and Electronic Government Success: An Empirical Study. Journal of Management Information Systems, 25, 99-131. https://doi.org/10.2753/MIS0742-1222250303

[8] DeLone, W.H. and McLean, E.R. (1992) Information Systems Success: The Quest for the Dependent Variable. Information Systems Research, 3, 60-95.

https://doi.org/10.1287/isre.3.1.60

[9] DeLone, W.H. and McLean, E.R. (2003) The DeLone and McLean Model of Information Systems Success: A Ten-Year Update. Journal of Management Information Systems, 19, 9-30. https://doi.org/10.1080/07421222.2003.11045748

[10] Ang, J. and Soh, P.H. (1997) User Information Satisfaction, Job Satisfaction and Computer Background: An Exploratory Study. Information \& Management, 32, 255-266. https://doi.org/10.1016/S0378-7206(97)00030-X

[11] Choe, J.-M. (1996) The Relationships among Performance of Accounting Information Systems, Influence Factors, and Evolution Level of Information Systems. Journal of Management Information Systems, 12, 215-239. https://doi.org/10.1080/07421222.1996.11518107

[12] Ragu-Nathan, T.S., Tarafdar, M., Ragu-Nathan, B.S. and Qiang, T. (2008) The Consequences of Technostress for End Users in Organizations: Conceptual Development and Empirical Validation. Information Systems Research, 19, 417-433. https://doi.org/10.1287/isre.1070.0165

[13] Marble, R.P. (2000) Operationalising the Implementation Puzzle: An Argument for Eclecticism in Research and in Practice. European Journal of Information Systems, 9, 132-147. https://doi.org/10.1057/palgrave.ejis.3000369

[14] McKeen, J.D., Guimaraes, T. and Wetherbe, J.C. (1994) The Relationship between User Participation and User Satisfaction: An Investigation of Four Contingency Factors. MIS Quarterly, 18, 427-451. https://doi.org/10.2307/249523

[15] Tesch, D., Miller, R., Jiang, J.J. and Klein, G. (2005) Perception and Expectation Gaps of Information Systems Provider Skills: The Impact on User Satisfaction. Information Systems Journal, 15, 343-355. https://doi.org/10.1111/j.1365-2575.2005.00201.x

[16] Juran, J.M. (1998) Juran on Planning for Quality. Free Press, New York.

[17] Zhang, P. and von Dran, G.M. (2000) Satisfiers and Dissatisfiers: A Two-Factor 
Model for Website Design and Evaluation. Journal of the American Society for Information Science, 51, 1253-1268. https://doi.org/10.1002/1097-4571(2000)9999:9999<::AID-ASI1039>3.0.CO;2-O

[18] Lee, S., Shin, B. and Lee, H.G. (2009) Understanding Post-Adoption Usage of Mobile Data Services: The Role of Supplier-Side Variables. Journal of the Association for Information Systems, 10, 860-888. https://doi.org/10.17705/1jais.00217

[19] Matzler, K. and Hinterhuber, H.H. (1998) How to Make Product Development Projects More Successful by Integrating Kano's Model of Customer Satisfaction into Quality Function Deployment. Technovation, 18, 25-38. https://doi.org/10.1016/S0166-4972(97)00072-2

[20] Zhang, P. and Fran, G.M.V. (2001) User Expectations and Rankings of Quality Factors in Different Web Site Domains. International Journal of Electronic Commerce, 6, 9-33. https://doi.org/10.1080/10864415.2001.11044237

[21] Tan, K.C. and Pawitra, T.A. (2001) Integrating SERVQUAL and Kano's Model into QFD for Service Excellence Development. Managing Service Quality, 11, 418-430. https://doi.org/10.1108/EUM0000000006520

[22] Oliver, R.L. (1977) Effect of Expectation and Disconfirmation on Postexposure Product Evaluations: An Alternative Interpretation. Journal of Applied Psychology, 62, 480-486. https://doi.org/10.1037/0021-9010.62.4.480

[23] Murry, J.W. and Hommons, J.O. (1995) Delphi: A Versatile Methodology for Conducting Qualitative Research. The Review of Higher Education, 18, 423-436. https://doi.org/10.1353/rhe.1995.0008

[24] Spreng, R.A., Thomas J. and Page, J. (2003) A Test of Alternative Measures of Disconfirmation. Decision Sciences, 34, 31-62. https://doi.org/10.1111/1540-5915.02214

[25] Chin, W.W. (2000) Frequently Asked Questions-Partial Least Squares and PLSGraph. http://disc-nt.cba.uh.edu/chin/plsfaq/plsfaq.htm

[26] Sia, C.L., Lim, K.H., Leung, K., Lee, M.K.O. and Huang, W.W. (2009) Web Strategies to Promote Internet Shopping: Is Cultural-Customization Needed? MIS Quarterly, 33, 491-512.

[27] Bardhan, I.R., Demirkan, H., Kannan, P.K. and Kauffman, R.J. (2010) Special Issue: Information Systems in Services. Journal of Management Information Systems, 26, 5-12. https://doi.org/10.2753/MIS0742-1222260401

[28] Weill, P. and Vitale, M. (2002) What IT Infrastructure Capabilities Are Needed to Implement E-Business Models? MIS Quarterly Executive, 1, 17-34.

[29] Montazemi, A.R. (1988) Factors Affecting Information Satisfaction in the Context of the Small Business Environment. MIS Quarterly, 12, 239-256. https://doi.org/10.2307/248849

[30] Kayworth, T. and Whitten, D. (2010) Effective Informationsecurity Requires a Balance of Social and Technology Factors. MIS Quarterly Executive, 9, 163-175.

[31] Wixom, B.H. and Todd, P.A. (2005) A Theoretical Integration of User Satisfaction and Technology Acceptance. Information Systems Research, 16, 85-102.

https://doi.org/10.1287/isre.1050.0042 


\section{Appendix}

\section{A1. Dimensions and Variables}

Name of
Dimension $\quad$ Definition of Dimension $\quad$ Name of Variable $\quad$ Definition of Variable

Dimension

MIS department and The support provided by the MIS System quality

information system department to the information system used for work and the features of the information system

Ease of use

Compatibility

Service quality

Company computer The policy and management

policy and

administration

Interpersonal relations and recognition

Work mechanism implemented to manage the information system used for work

Security policy

Training

Management support

Relationships with others and their views after using the information system for work
Computer policy

Levels of accessibility, reliability, response time, flexibility, and integration of the information system currently used for work.

The level of ease of use relating to the operation interfaces of the information system currently used for work.

The compatibility of experiences between the system currently used for work and the system used before (e.g., similar interface operations).

The level of support and services provided by the company's MIS department, including the following:

Reliability: The ability to fulfill the service promise without errors.

Responsiveness: The enthusiasm of MIS personnel when expressing willingness to help users and ability to provide immediate services.

Assurance: Professional knowledge and manner of MIS personnel that develops trust and confidence among users. Empathy: The level of care and attention given to users.

Whether the company has a reward/punishment system for using the information system (and level).

Whether the company has a security protection system for operating the information system.

Whether the company has a training system for operating the information system.

Encouragement given by management to employees regarding the use of the information system.

Customer relations

Changes in the relationships with the people engaged in business transactions after using the current information system for work.

Supervisor relations Changes in the relationships with supervisors after using the current information system for work.

Supervisor Recognition from the supervisor for the employees' attitude and recognition performance regarding the use of the current information system for work.

Personal recognition Personal recognition of the ability to use the current information system for work.

Changes in job execution or control Information quality The level of accuracy, completeness, and currency, as after using the information system for work information system for work.

Perceived usefulness The perceived level of usefulness of the system after using the current information system for work.

Confirmation of The perceived level of confirmation/disconfirmation for meeting expectation expectations after using the current information system for work.

Uncertainty The perceived level of increase/decrease in unfamiliarity toward work after using the current information system for work. 


\section{Continued}

\begin{tabular}{|c|c|c|c|}
\hline & & Complexity & $\begin{array}{l}\text { The perceived level of changes in the complexity of work after } \\
\text { using the current information system for work. }\end{array}$ \\
\hline & & Autonomy & $\begin{array}{l}\text { The perceived level of changes in autonomy at work after using } \\
\text { the current information system for work. }\end{array}$ \\
\hline & & Feedback & $\begin{array}{l}\text { The perceived level of increase in the speed of gaining feedback } \\
\text { on work status or performance reports after using the current } \\
\text { information system for work. }\end{array}$ \\
\hline & & Power & $\begin{array}{l}\text { The perceived level of changes in power and status after using } \\
\text { the current information system for work. }\end{array}$ \\
\hline & & Role conflict & $\begin{array}{l}\text { The perceived level of changes and limitations in work processes } \\
\text { after using the current information system for work. }\end{array}$ \\
\hline \multirow[t]{2}{*}{ Performance } & $\begin{array}{l}\text { The changes in work effectiveness } \\
\text { after using the information system }\end{array}$ & Effectiveness & $\begin{array}{l}\text { The perceived level of changes in work quality after using the } \\
\text { current information system for work. }\end{array}$ \\
\hline & for work & Efficiency & $\begin{array}{l}\text { The perceived level of changes in work speed after using the } \\
\text { current information system for work. }\end{array}$ \\
\hline \multirow[t]{5}{*}{$\begin{array}{l}\text { Advancement and } \\
\text { growth }\end{array}$} & $\begin{array}{l}\text { The security and growth gained } \\
\text { after using the information system }\end{array}$ & Work security & $\begin{array}{l}\text { The perceived level of protection in work rights after using the } \\
\text { current information system for work. }\end{array}$ \\
\hline & for work. & Work replacement & $\begin{array}{l}\text { The perceived level of possibility of being replaced by the } \\
\text { information system after using the current information system } \\
\text { for work. }\end{array}$ \\
\hline & & $\begin{array}{l}\text { Computer skill } \\
\text { growth }\end{array}$ & $\begin{array}{l}\text { The perceived level of skills and technical abilities learned after } \\
\text { using the current information system for work. }\end{array}$ \\
\hline & & Work skill growth & $\begin{array}{l}\text { The perceived level of work skills learned after using the current } \\
\text { information system for work. }\end{array}$ \\
\hline & & Self-efficacy & $\begin{array}{l}\text { The perceived level of confidence in one's own ability to } \\
\text { complete the task after using the current information system for } \\
\text { work. }\end{array}$ \\
\hline
\end{tabular}




\section{A2. Questionnaire}

Dear Sir/Madam,

This is a questionnaire for an academic study on factors relating to information system satisfaction. The research results are expected to make significant contributions to academic development and industrial practices. Your answers will be valuable references for us, and your assistance will be of great help to this research. We sincerely invite you to complete this survey in your free time. Thank you.

There are two pages in this questionnaire, dividing the questions into two parts. Please answer the questions based on your experience of an information system you have recently started to use or the information system you have used most often. The information you provide in this survey will only be used for collective statistical analysis and will not be disclosed individually. Be assured that your information is safe with us. We would like to thank you again for your participation.

To express our appreciation for your help, we have prepared convenience store gift vouchers, each to the value of NT $\$ 100$. We will randomly draw 100 winners from the respondents.

Part 1: Basic Information

1. Sex: $\square$ Male $\square$ Female

2. Age: ___ years old

3. Education: $\square$ High school/occupational high school or below

$\square$ Associate degree $\square$ Bachelor's degree $\square$ Master's degree or higher $\square$ Others

4. Professional background:
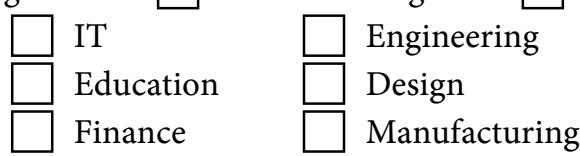

$\square$ (Business administration

$\square$ Business administration

\begin{tabular}{lll} 
& & \\
5. Industry & Education \\
\hline & IT & Finance
\end{tabular} Manufacturing

Others

6. Size of company (no. of employees):

$\square$ Services $\square$ Others

7. Function:

8. Job title:

9. Years of work experience: ____ years

10. Years of computer experience: years

11. Please consider the information system you have started to use recently (or use most often) that you have designated for this survey. What are the major tasks that you use this system to complete at work?

12. How long have you been using this system? years

13. Are you satisfied or dissatisfied with this information system? $\square$ Satisfied $\square$ Dissatisfied

(If you answered "satisfied," please proceed to question 14. If you answered "dissatisfied," pleas skip to question 15)

14. How satisfied you are with this information system?
$\square$ A little satisfied
Somewhat satisfied
Satisfied
Very satisfied
Extremely satisfied

15. How dissatisfied you are with this information system?

\begin{tabular}{|ll}
$\square$ A little dissatisfied $\square$ Somewhat dissatisfied $\square$ Dissatisfied \\
Very dissatisfied \\
Extremely dissatisfied
\end{tabular}

16. If you wish to participate in the lucky draw, please leave your email: 


\section{Part 2}

Please consider the information system you designated in question 11 of Part 1 when answering the following questions. Please tick the answer that most closely represents your perception (single choice). If you have not had the experience described in the question, please tick "unable to answer."

1 The system's quality is better/worse than I expected.

2 The data accessibility is better/worse than I expected.

3 The system's reliability is better/worse than I expected.

4 The system's response speed is better/worse than I expected.

5 The system's customizability is better/worse than I expected.

6 The system's data integration is better/worse than I expected.

7 The systems' ease of use is better/worse than I expected.

8 The similarity between the system's user interface and functions and those of systems I have experienced before is better/worse than I expected.

9 Regarding this system, the quality of the services provided by the MIS Department of my company is better/worse than I expected.

10 Regarding this system, the MIS Department's ability to fulfill the promises they made is better/worse than I expected.

11 Regarding problems with this system, the MIS Department's ability to provide instant and relevant services is better/worse than I expected.

12 My trust in the MIS personnel of my company to deal with problems with this system is better/worse than I expected.

13 The MIS personnel's attention to my personal use of the system is better/worse than I expected.

14 Regarding this system, my company's system for reward and punishment for correctly using the system is better/worse than I expected.

15 My company's security policy for using this system is better/worse than I expected.

16 My company's training and education for operating this system is better/worse than I expected.

17 Resource support for using this system provided by the managers of my company is better/worse than I expected.

18 My relationships with business colleagues and partners after using this system were better/worse than I expected.

19 My relationship with my supervisor after using this system is better/worse than I expected.

20 My supervisor's recognition of my attitude and performance exhibited for using this system is better/worse than I expected.

21 My self-recognition for using this system is better/worse than I expected.

22 The quality of the information provided by this system is better/worse than I expected.

The accuracy of the information provided by this system is better/worse than I expected.

The completeness of the information provided by this system is better/worse than I expected.

The currency of the information provided by this system is better/worse than I expected.

The clarity of the information provided by this system is better/worse than I expected.

The usefulness of this system for work is better/worse than I expected.

Overall, this system as used for work is better/worse than I expected.

After using this system, the clarity of my job content is better/worse than I expected.

30 After using this system, the level of job simplification is better/worse than I expected.

31 After using this system, the ability to manage my own time is better/worse than I expected.

32 After using this system, the level of feedback on the effectiveness of my work is better/worse than I expected.

33 After using this system, the increase in my power and status is better/worse than I expected. 


\section{Continued}

34 After using this system, the clarity of my role and duties is better/worse than I expected.

35 After using this system, the quality of my work is better/worse than I expected.

36 After using this system, my working speed is better/worse than I expected.

37 After using this system, my job security is better/worse than I expected.

38 After using this system, my sense of being replaced by the information system is better/worse than I expected.

39 After using this system, my computer abilities and technical skills are better/worse than I expected.

40 After using this system, the level of work-related knowledge and technical skills learned is better/worse than I expected.

41 After using this system, my confidence in completing work tasks is better/worse than I expected. 


\section{A3. Regression Analysis and T Test on Each Factor}

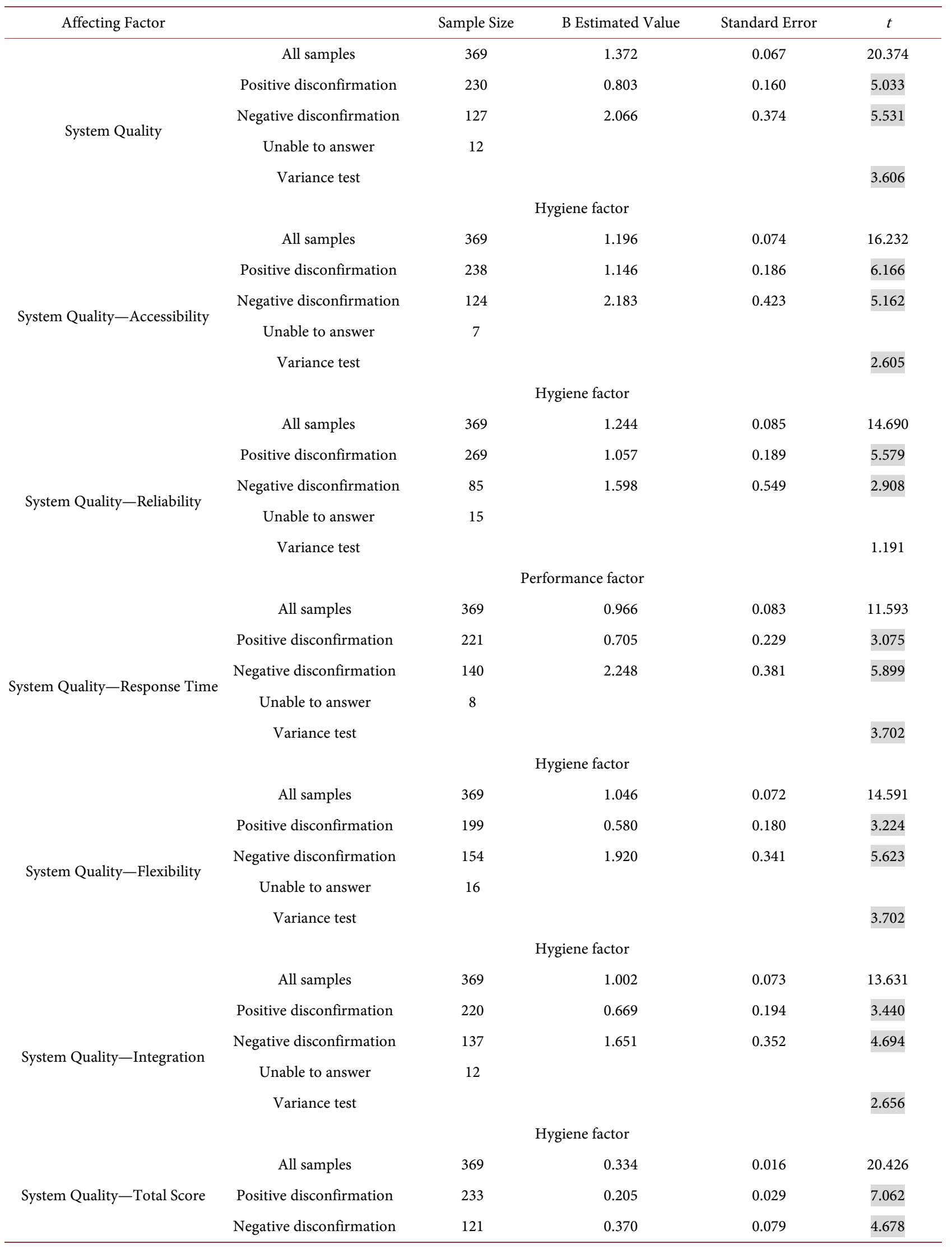




\section{Continued}

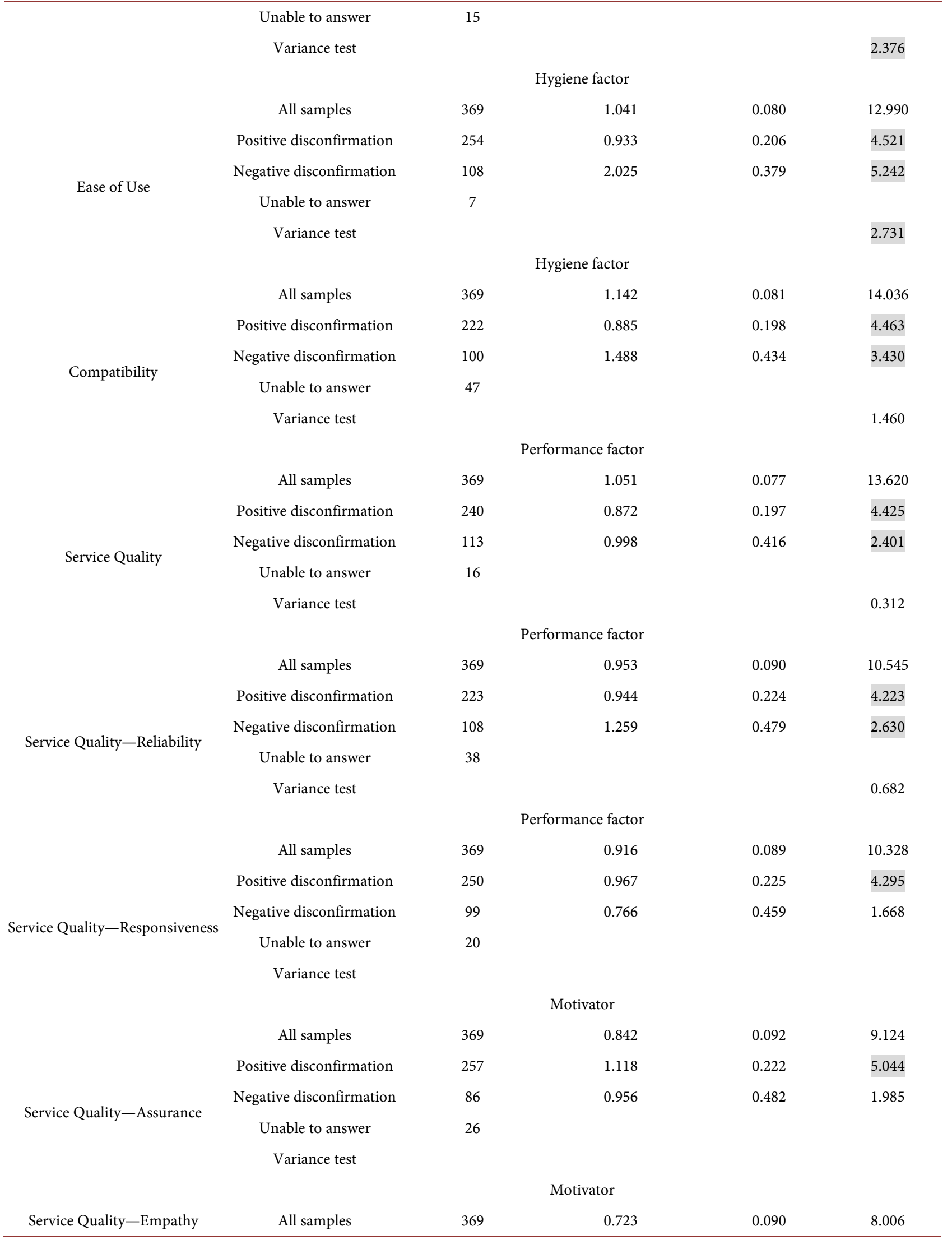




\section{Continued}

\begin{tabular}{|c|c|c|c|c|c|}
\hline & Positive disconfirmation & 191 & 0.660 & 0.261 & 2.524 \\
\hline & Negative disconfirmation & 131 & 0.940 & 0.385 & 2.441 \\
\hline & Unable to answer & 47 & & & \\
\hline & Variance test & & & & 0.626 \\
\hline & & & e factor & & \\
\hline & All samples & 369 & 0.291 & 0.025 & 11.494 \\
\hline & Positive disconfirmation & 240 & 0.295 & 0.055 & 5.378 \\
\hline & Negative disconfirmation & 98 & 0.188 & 0.107 & 1.757 \\
\hline 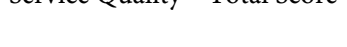 & Unable to answer & 31 & & & \\
\hline & Variance test & & & & \\
\hline & & & & & \\
\hline & All samples & 369 & 0.808 & 0.097 & 8.364 \\
\hline & Positive disconfirmation & 153 & 0.319 & 0.255 & 1.252 \\
\hline Computar Dolicur & Negative disconfirmation & 111 & 0.445 & 0.426 & 1.043 \\
\hline & Unable to answer & 105 & & & \\
\hline & Variance test & & & & \\
\hline & & & actor & & \\
\hline & All samples & 369 & 0.848 & 0.090 & 9.377 \\
\hline & Positive disconfirmation & 239 & 0.826 & 0.207 & 3.991 \\
\hline Cocunitu Dolicur & Negative disconfirmation & 88 & 0.309 & 0.522 & 0.592 \\
\hline & Unable to answer & 42 & & & \\
\hline & Variance test & & & & \\
\hline & & & & & \\
\hline & All samples & 369 & 0.730 & 0.084 & 8.700 \\
\hline & Positive disconfirmation & 182 & 0.742 & 0.237 & 3.127 \\
\hline Trnining & Negative disconfirmation & 162 & 1.030 & 0.353 & 2.920 \\
\hline & Unable to answer & 25 & & & \\
\hline & Variance test & & & & 0.692 \\
\hline & & & e factor & & \\
\hline & All samples & 369 & 0.815 & 0.091 & 8.946 \\
\hline & Positive disconfirmation & 237 & 0.720 & 0.225 & 3.202 \\
\hline Manorement Sunnort & Negative disconfirmation & 102 & 1.117 & 0.433 & 2.581 \\
\hline & Unable to answer & 30 & & & \\
\hline & Variance test & & & & 0.894 \\
\hline & & & e factor & & \\
\hline & All samples & 369 & 1.131 & 0.109 & 10.366 \\
\hline & Positive disconfirmation & 234 & 1.066 & 0.236 & 4.517 \\
\hline Customer Relations & Negative disconfirmation & 68 & 1.039 & 0.685 & 1.516 \\
\hline & Unable to answer & 67 & & & \\
\hline & Variance test & & & & \\
\hline
\end{tabular}




\section{Continued}

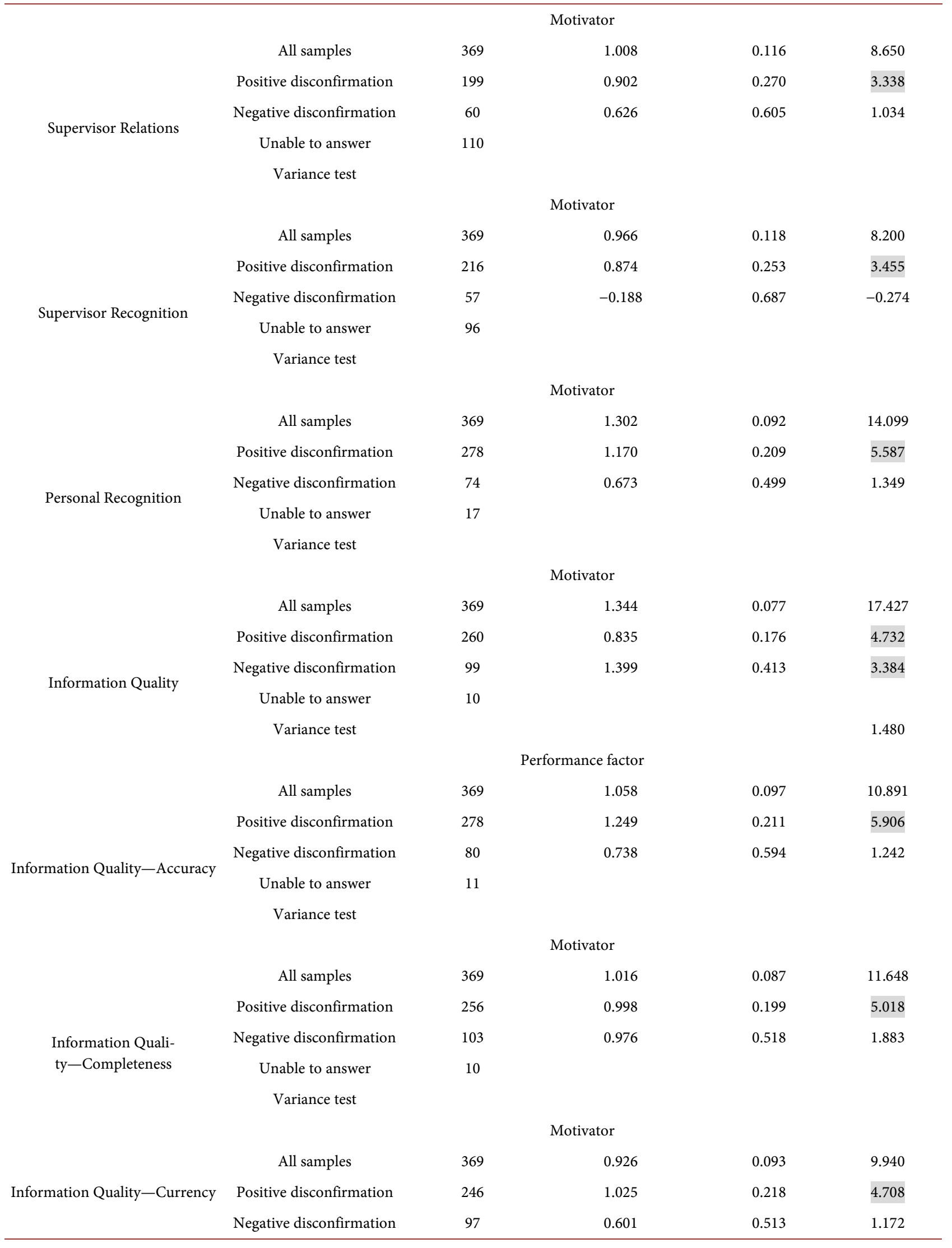




\section{Continued}

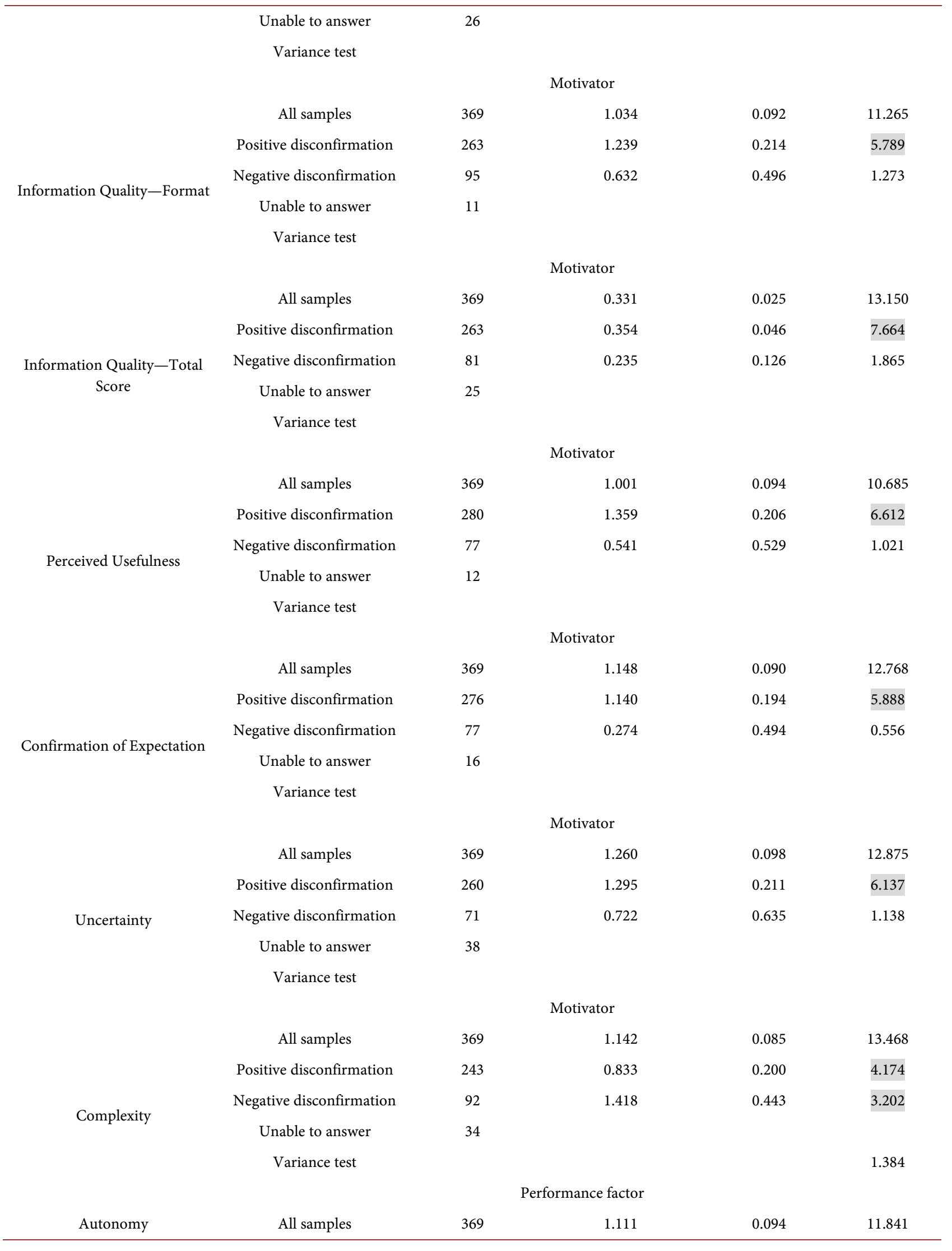




\section{Continued}

Feedback

Role Conflict

Effectiveness

Efficiency

Work Security
Positive disconfirmation
Negative disconfirmation

Unable to answer

Variance test

$$
\text { All samples }
$$

Positive disconfirmation

Negative disconfirmation

Unable to answer

Variance test

$$
\text { All samples }
$$

Positive disconfirmation

Negative disconfirmation

Unable to answer

Variance test

\section{All samples}

Positive disconfirmation

Negative disconfirmation

Unable to answer

Variance test

$$
\text { All samples }
$$

Positive disconfirmation

Negative disconfirmation

Unable to answer

Variance test

\section{All samples}

Positive disconfirmation

Negative disconfirmation

Unable to answer

Variance test

$$
\text { All samples }
$$

Positive disconfirmation

Negative disconfirmation

Unable to answer

Variance test

\section{9}

87

73

369

219

80

70

369

132

69

168

369

206

76

87

369

266

59

44

369

258

68

43

369

183

64

122

Motivator

$\begin{array}{lll}1.183 & 0.096 & 12.277 \\ 1.142 & 0.232 & 4.924 \\ 0.942 & 0.550 & 1.715\end{array}$

Motivator

$\begin{array}{ccc}0.700 & 0.124 & 5.646 \\ 0.445 & 0.365 & 1.217 \\ -0.043 & 0.524 & -0.081\end{array}$

\section{Useless factor}

$\begin{array}{lll}0.911 & 0.111 & 8.199 \\ 1.042 & 0.265 & 3.937 \\ 0.289 & 0.567 & 0.509\end{array}$

Motivator

$\begin{array}{ccc}1.136 & 0.113 & 10.062 \\ 1.124 & 0.238 & 4.722 \\ 0.729 & 0.615 & 1.187\end{array}$

Motivator

$\begin{array}{lll}1.075 & 0.100 & 10.780 \\ 1.299 & 0.223 & 5.812 \\ 1.022 & 0.529 & 1.931\end{array}$

Motivator

$\begin{array}{lll}0.981 & 0.120 & 8.179 \\ 0.849 & 0.300 & 2.833 \\ 0.189 & 0.589 & 0.321\end{array}$

Motivator 